\title{
Ocular fundus in neurofibromatosis type 2
}

\author{
Klara Landau, Gazi M Yaşargil
}

\begin{abstract}
Several ocular findings have been associated with neurofibromatosis type 2 (NF 2) since the identification of this disease as a distinct clinical entity. Juvenile cataracts were reported first, followed by combined pigment epithelial and retinal hamartomas. In a recent report, epiretinal membranes were described in seven of nine patients. Moreover, an association between NF 2 and optic disc gliomas has been suggested based on earlier published reports. Six patients with a confirmed diagnosis of NF 2 were examined. Four patients (six of 12 eyes) had epiretinal membranes and one had an optic disc glioma. In addition, one case of an optic disc glioma in a patient with NF 2 was tracked. It is concluded that epiretinal membranes are frequent in NF 2, and that optic disc glioma is a rare but specific sign of NF 2. Patients at risk for development of this disease should undergo careful examination of the ocular fundus.

(Br F Ophthalmol 1993; 77: 646-649)
\end{abstract}

New data concerning the gene defects in neurofibromatosis have led to recognition of two separate entities: neurofibromatosis type 1 (NF 1) and neurofibromatosis type 2 (NF 2). These distinct forms of neurofibromatosis are caused by gene defects on different chromosomes. In NF 1 the gene defect is located in the pericentromeric region of chromosome 17; in NF 2 the gene defect is located on the long arm of chromosome $22 .^{12}$ The cardinal finding in NF 2 is bilateral acoustic neuromas. Their identification, even in the absence of other findings, clinches the diagnosis of NF $2 .^{3}$ Other central nervous system tumours associated with NF 2 include meningiomas, gliomas, and schwannomas. Café au lait spots and skin neurofibromas may develop but iris hamartomas are associated almost exclusively with NF 1.

In 1986 and 1989 Kaiser-Kupfer and her colleagues described juvenile posterior capsular lens opacities in patients with NF 2. ${ }^{45}$ This observation provided the first report of an ocular abnormality in NF 2. An association was later proposed between combined pigment epithelial and retinal hamartomas (CPERH) and NF $2 .^{6}$ This finding was confirmed by several authors. ${ }^{7-9}$ Recently epiretinal membranes were reported in seven of nine patients with NF $2 .{ }^{10}$ An association was also suggested between optic disc glioma and NF 2. This observation was based on early published reports without providing a new case. ${ }^{11}$ In this current study we examined patients with NF 2 to further define the ocular phenotype of this disease.

\section{Patients and methods}

Between September 1991 and June 1992 we prospectively examined six consecutive patients with NF 2. Nobody was excluded from the study. All patients were admitted to the neurosurgery department, except for patient 5 who had the eye examination while visiting her father (patient 4). The diagnosis was confirmed by neurosurgical biopsy in four patients and by neuroimaging in two. Patients 4 and 5 were father and daughter, the remaining four were unrelated. The eye examination included determination of visual acuity, biomicroscopy before and after pupillary dilatation with special attention to the presence of iris hamartomas and lens opacities, and dilated fundus examination. Patients 2, 3, and 6 had fluorescein angiography. The severity of epiretinal membranes was graded according to Gass ${ }^{12}$ into grade 0 ('cellophane' maculopathy), grade 1 ('crinkled cellophane' maculopathy), and grade 2 ('macular pucker').

\section{Results}

The findings are summarised in Table 1. The four men and two women ranged in age from 22 to 63 years. Cataracts were found in six of 12 eyes (three of six patients), the opacities being cortical in four eyes and subcapsular in two eyes. No Lisch nodules were seen. An epiretinal membrane was observed in six of 12 eyes (four of six patients). All membranes involved the macular region and their severity ranged from grade 0 to grade 2. Patient 1 had bilateral epiretinal membranes of grade 0 , patient 3 had bilateral membranes of grade 1 in the right eye and grade 2 in

Table 1 Summary of cases

\begin{tabular}{|c|c|c|c|c|c|c|c|c|c|}
\hline \multirow{2}{*}{$\begin{array}{l}\text { Patient/age } \\
(\text { years)/sex }\end{array}$} & \multicolumn{2}{|c|}{ Visual acuity } & \multicolumn{2}{|c|}{ Presence of cataract } & \multicolumn{2}{|c|}{$\begin{array}{l}\text { Presence of epiretinal } \\
\text { membranes/grade }\end{array}$} & \multicolumn{2}{|l|}{ Other fundus findings } & \multirow[b]{2}{*}{ Remarks } \\
\hline & Right & Left & Right & Left & Right & Left & Right & Left & \\
\hline $\begin{array}{l}1 / 53 / \mathrm{M} \\
2 / 22 / \mathrm{M} \\
3 / 30 / \mathrm{M} \\
4 / 63 / \mathrm{M} \\
5 / 33 / \mathrm{F} \\
6 / 37 / \mathrm{F}\end{array}$ & $\begin{array}{l}20 / 20 \\
20 / 20 \\
20 / 25 \\
20 / 20 \\
20 / 15 \\
\mathrm{HM}\end{array}$ & $\begin{array}{l}20 / 20- \\
20 / 200 \\
20 / 30 \\
20 / 20- \\
20 / 15 \\
20 / 100\end{array}$ & $\begin{array}{l}\text { No } \\
\text { Yes } \\
\text { Yes } \\
\text { No } \\
\text { No } \\
\text { Yes }\end{array}$ & $\begin{array}{l}\text { No } \\
\text { Yes } \\
\text { Yes } \\
\text { No } \\
\text { No } \\
\text { Yes }\end{array}$ & $\begin{array}{l}\text { Yes/0 } \\
\text { No } \\
\text { Yes/1 } \\
\text { No } \\
\text { No } \\
\text { No }\end{array}$ & $\begin{array}{l}\text { Yes/0 } \\
\text { Yes/2 } \\
\text { Yes/2 } \\
\text { No } \\
\text { No } \\
\text { Yes/2 }\end{array}$ & $\begin{array}{l}\text { Hyperpigmentation } \\
\mathbf{P} \\
\mathbf{P} \\
\text { Optic disc glioma }\end{array}$ & $\begin{array}{l}\text { OA } \\
\text { P, Astrocytic hamartoma } \\
\text { P }\end{array}$ & $\begin{array}{l}\text { Perioptic meningioma, left eye } \\
\text { Father of patient } 5 \\
\text { Daughter of patient } 4\end{array}$ \\
\hline
\end{tabular}

$\mathrm{P}=$ papilloedema $\mathrm{OA}=$ optic atrophy $\mathbf{H M}=$ hand movements

Grading of epiretinal membranes according to Gass. ${ }^{.2}$ 
Figure 1 Fundus photograph of the left eye of patient 2, demonstrating an epiretinal membrane in the centre and in the inferotemporal portion of the macula. The disc is pale due to an optic nerve sheath meningioma.

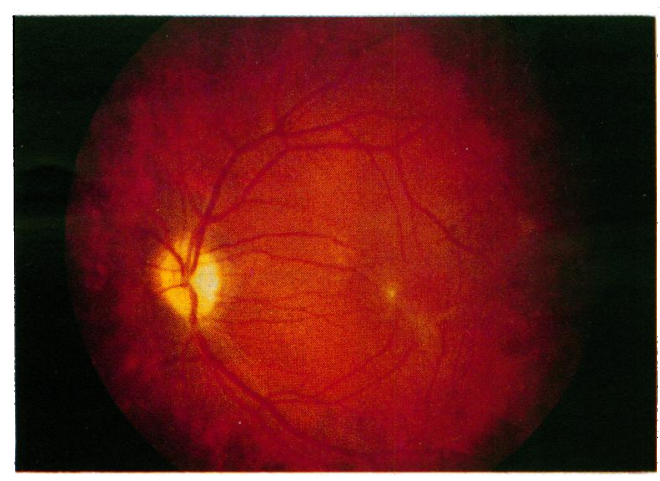

the left eye, and patients 2 and 6 had unilateral membranes of grade 2 . None of the grade 2 membranes caused retinal oedema, haemorrhages, exudates, or serous detachment of the retina as observed both biomicroscopically and angiographically (Figs 1-3).

Several ocular abnormalities resulting from bilateral acoustic neuromas and/or other CNS tumours were found. These included papilloedema, optic atrophy, impaired motility, pupillary abnormalities, nystagmus, and lid function disturbances. We present three cases in detail.

CASE 2

A 22-year-old man was admitted to the neurosurgery department for removal of a left perioptic meningioma. Thirteen years earlier, he had undergone surgery for a spinal tumour, and since the age of 18 multiple cranial nerve palsies had developed. His hearing was reduced bilaterally and magnetic resonance imaging (MRI) showed bilateral eighth nerve masses, left optic nerve sheath meningioma, and multiple tumours of lower cranial nerves.

Best corrected visual acuity was $20 / 20$ in the right eye and 20/200 in the left eye. There was a left relative afferent pupillary defect. The left eye had moderate lagophthalmos and exophthalmos, and motility was severely reduced. There was mild central subcapsular cataract in the right eye and a dense peripheral cortical cataract in the left eye. The right fundus was normal except for marked hyperpigmentation in the nasal part of the posterior pole. The left optic disc appeared atrophic. Overlying the left macula was an epiretinal membrane (Fig 1). On fluorescein angiography capillaries appeared to be dragged

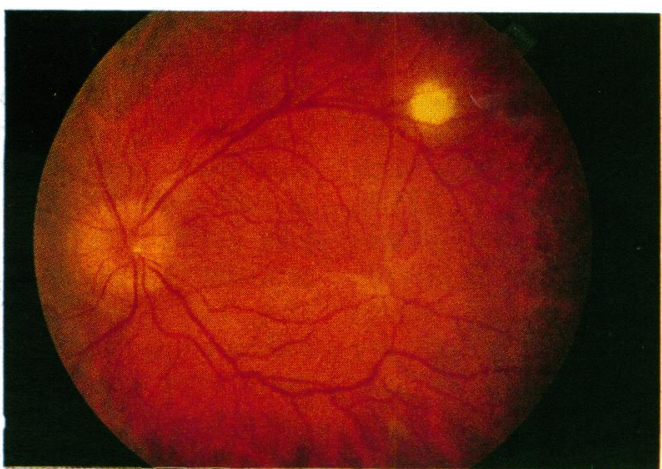

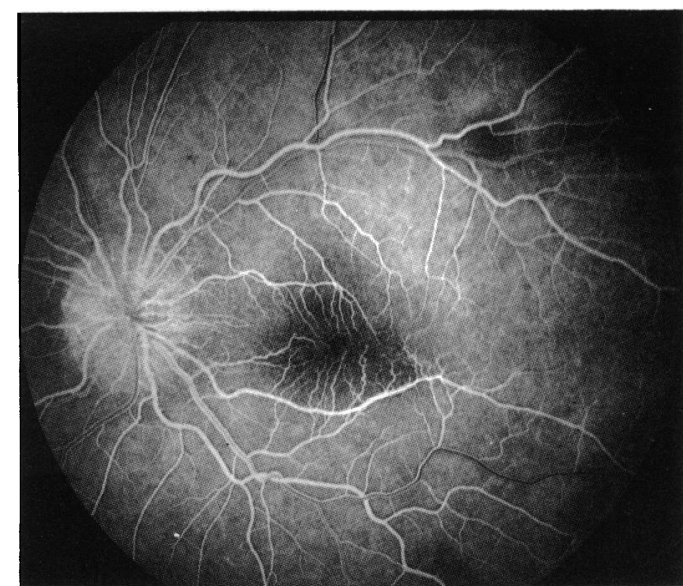

Figure 3 Fluorescein angiogram of the left eye of patient 3 demonstrating retinal vessels inside the foveal avascular zone. There is blockage of fluorescence corresponding to the superotemporal lesion which in later stages showed increasing leakage.

towards the centre of the macula, and there was no leakage.

CASE 3

A 30-year-old man underwent emergency surgery for a giant right acoustic neuroma with signs of increased intracranial pressure. Six years earlier, a left acoustic neuroma had been removed. MRI revealed additional tumours on other cranial nerves, in the left temporal lobe, the medulla, and the spinal cord.

Best corrected visual acuity was $20 / 25$ in the right eye and 20/30 in the left eye. There was mild bilateral facial paresis. Bilateral cataracts were present. The opacity was central subcapsular in the right eye and peripheral cortical in the left eye. There was bilateral papilloedema. In the right eye a subtle greyish epiretinal membrane was seen superiorly to the fovea and a 'crinkled cellophane' appearance was noted between the temporal arcades. The left fundus showed a semitranslucent epiretinal membrane over the entire macula with a Swiss cheese-like hole temporal to the fovea. In addition, a round white lesion was located temporosuperiorly (Fig 2). On a fundus photograph of left eye taken 2 years previously, no papilloedema and no folds between disc and macula were found, but the epiretinal membrane and the white lesion appeared identical. On fluorescein angiography of the left eye the abnormal vascular pattern in the macula was clearly seen (Fig 3 ). The white lesion showed early blockage and late leakage of dye. We believe that the lesion represents an astrocytic hamartoma.

\section{CASE 6}

A 37-year-old woman was referred for evaluation of progressive ataxia and hearing loss. She had had surgery for a right acoustic neuroma 7 years previously and a right glossopharyngeal neuroma 1 year later. There was neuroradiological evidence of recurrent acoustic neuroma on the right, an acoustic neuroma on the left, bilateral trigeminal neuromas, a spinal neuroma at the $\mathrm{C} 1$ level, and an arachnoid cyst in the left temporal lobe. There was a right abducens and 
Figure 4 Fundus photograph of the right eye of patient 6 shows a large smooth white gliotic tumour overlying the disc.

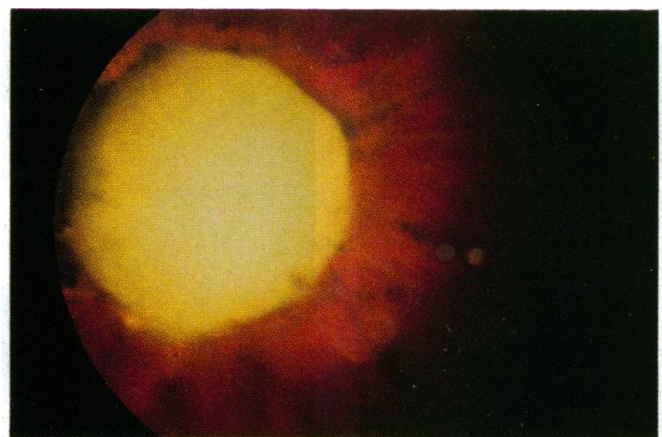

bilateral facial palsy. A partial right tarsorrhaphy had been performed previously. The patient gave a history of poor vision in her right eye since childhood.

Best corrected visual acuity was hand movements in the right eye and 20/100 in the left eye. The right cornea had a superficial peripheral scar but was clear centrally. Both lenses had posterior cortical opacities which were paracentral in the right eye and peripheral in the left eye. In the right eye funduscopy revealed a large white tumour covering the disc (Fig 4). The tumour measured $4 \times 4$ disc diameters and was prominent. Its surface was smooth. The vessels emerging from below the tumour looked stretched and gliotic and the visible retina was atrophic. In the left eye there was an epiretinal membrane in the macula. Fluorescein angiography showed capillaries overlying the foveal avascular zone.

While reviewing our clinic's slide collection we found a photograph of a disc tumour, smaller in size but similar to the one in the right fundus of patient 6. It was taken in 1962 and was labelled with the patient's name, date of birth, and the title: 'Disc tumour in Morbus Von Recklinghausen'. We tracked the patient's record and found that she died in 1967 following an operation for a left acoustic neuroma. A right acoustic neuroma had been removed 5 years previously. She thus had NF 2. At the time when the picture was taken she was 20 years old.

\section{Discussion}

Juvenile cataracts are common in patients with NF $2 .^{5}$ Accordingly, they are listed as additional signs contributing to the diagnosis of this disease in young patients with first degree relatives with NF 2 and unilateral acoustic neuroma. ${ }^{3}$ In older patients, cataracts have less diagnostic value owing to their increasing frequency in the general population.

Combined pigment epithelial and retinal hamartoma (CPERH) has been identified in NF 2. This association was based on a new case $^{6}$ and on the retrospective identification of a second case from published reports. ${ }^{13}$ Since then several authors reported the occurrence of CPERH in patients with NF $2 .^{7-9}$ In one case the tumour was discovered in a 1-year-old child 6 years before the diagnosis of NF2. ${ }^{8}$ These impressive lesions typically occur in the posterior pole and involve both the deep and superficial retinal layers. Epiretinal membranes occur with CPERHs in $78 \%$ of cases. ${ }^{14}$
Kaye et al recently reported epiretinal membranes in seven of nine patients with NF $2 .{ }^{10}$ One patient's eye was studied histologically, and intraretinal glial proliferation with an overlying epiretinal membrane was found, consisting of astrocytic cells with positive staining for glial fibrillary acid protein. The authors propose that this may represent an early glial hamartoma, but they point out that this patient's clinical appearance of the epiretinal membrane was the most severe and that it may not be representative for epiretinal membranes in NF 2 . In our study, three of the six eyes with epiretinal membranes were similar in severity, showing a definite grey or white membrane which obscured the underlying retinal vessels and caused marked retinal distortion. None of these three patients had fluorescein leakage, similar to the one patient who had fluorescein angiography in Kaye et al's series. We also looked for associated disturbance at the level of the retinal pigment epithelium (RPE), but did not find definite RPE abnormalities in the involved eyes. We thus cannot conclude whether epiretinal membranes found in patients with NF 2 are an abortive form of CPERHs or whether they represent an isolated entity.

Idiopathic epiretinal membranes occur predominantly in patients older than 50 years and their incidence rises with increasing age. ${ }^{12}$ Young patients without posterior vitreous detachment rarely develop epiretinal membranes, but such membranes of presumably congenital origin in children and young adults have been described..$^{1216}$ Formation of epiretinal membranes occurs in a variety of ocular conditions such as retinal vascular diseases, retinal tears, rhegmatogenous retinal detachment, vitreous inflammatory diseases, ocular trauma, intraocular tumours, and tapetoretinal degenerations. ${ }^{12}$ In the present study the six eyes with epiretinal membranes had no ocular conditions implicated in epiretinal membrane formation.

The histopathology of epiretinal membranes has been extensively studied. ${ }^{17-21}$ Definite identification of the cells of origin is difficult owing to the ability of retinal glial and RPE cells to change into cells with a similar appearance and function. ${ }^{12} \mathrm{NF} 2$ is a disease in which extensive proliferation of glial cells in the central nervous system occurs and it is thus not surprising if a similar process occurs in the retina which constitutes a part of the central nervous system.

It is remarkable that patients 4 and 5 did not show any specific ocular signs of NF 2. They both represent the only familial cases in this study as opposed to the remaining four cases which are sporadic. The mother of patient 4 was deaf and died of a brain tumour. Patient 4 did not have a neurosurgical procedure until the age of 62. His 33-year-old daughter, patient 5 , was diagnosed only because of the positive family history and is almost asymptomatic. Another 38year-old daughter is known to harbour bilateral acoustic neuromas; she refused an eye examination. The disease in this family seems to run a milder course and not to show ocular manifestations when compared with the new mutation cases.

We believe that the disc tumour in the right eye 
of patient 6 and the photograph of a tumour found in the slide collection both represent examples of optic disc gliomas. It has been suggested that these extremely rare tumours may be found specifically in patients with NF $2 .{ }^{11}$ This assumption was based on reports published long before the identification of NF 2 as a distinct disease. ${ }^{22-24}$ The three reported patients were all deaf and had additional features which retrospectively put them into the diagnostic category of NF 2.

We conclude that epiretinal membranes represent a frequent sign in NF 2, thus confirming the report by Kaye et al. ${ }^{10}$ These membranes are possibly of congenital origin similar to those previously reported in healthy children and young adults. In a larger study the frequency and specificity of epiretinal membranes as a sign of NF 2 should be evaluated.

We further provide two new cases of optic disc gliomas in patients with a confirmed diagnosis of NF 2. These rare tumours are specific for the disease and should thus be added to the list of ocular manifestations of NF 2.

This study was presented at the 9th International NeuroOphthalmology Symposium in Williamsburg, Virginia, 28 June3 July 1992.

We thank Drs William F Hoyt, Jonathan C Horton, and Balder $\mathrm{P}$ Gloor for helpful comments, and Mr Peter Bär for excellent photography.

1 Barker D, Wright E, Nguyen K, Cannon L, Fain P, Goldgar $\mathrm{D}$, et al. Gene for von Recklinghausen neurofibromatosis is in the pericentromeric region of chromosome 17. Scienc 1987; 236: 1100-2.

2 Rouleau GA, Wertelecki W, Haines JL, Hobbs WJ, Trofatte JA, Seizinger BR, et al. Genetic linkage of bilateral acoustic neurofibromatosis to a DNA marker on chromosome 22 Nature 1987: 329: 246-8.

3 National Institutes of Health Consensus Development Conference on Neurofibromatosis: Conference Statement. Arch Neurol 1988; 45: 575-8.

4 Pearson-Webb MA, Kaiser-Kupfer MI, Eldridge R. Eye findings in bilateral acoustic (central) neurofibromatosis: association with presenile lens opacities and cataracts but absence of Lisch nodules. N Engl F Med 1986; 315: 1553-4
Kaiser-Kupfer M, Freidlin V, Datiles MB, Edwards PA Sherman JL. Parry D, et al. The association of posterior capsular lens opacities with bilateral acoustic neuromas in patients with neurofibromatosis type 2. Arch Ophthalmo 1989; 107: 541-4.

6 Landau K, Dossetor FM, Hoyt WF, Muci-Mendoza R. Retinal hamartoma in neurofibromatosis 2. Arch Ophthalmol 1990; 108: 328-9.

7 Good WV, Brodsky MC, Edwards MS, Hoyt WF. Bilateral retinal hamartomas in neurofibromatosis type 2. Brf Ophthalmol 1991; 75: 190 .

8 Sivalingam A, Augsburger J, Perilongo G, Zimmerman R, Barabas G. Combined hamartoma of the retina and retinal pigment epithelium in a patient with neurofibromatosi type 2. F Pediatr Ophthalmo

9 Bouzas EA, Parry DM, Eldridge R, Kaiser-Kupfer MI. Familial occurrence of combined pigment epithelial and retinal hamartomas associated with neurofibromatosis 2 . Retina 1992; 12: 103-7.

10 Kaye LD, Rothner AD, Beauchamp, Meyers SM, Estes ML. Ocular findings associated with neurofibromatosis type II. Ophthalmology 1992; 99: 1424-9.

11 Dossetor FM, Landau K, Hoyt WF. Optic disk glioma in neurofibromatosis type 2. Am $\mathcal{F}$ Ophthalmol 1989; 108: 602-3.

12 Gass JDM. Macular dysfunction caused by epiretinal membrane contraction. In: Klein EA, ed. Stereoscopic atlas of macular diseases: diagnosis and treatment. St Louis: Mosby, macular diseases:

13 Cotlier E. Café-au-lait spots of the fundus in neurofibromatosis. Arch Ophthalmol 1977; 95: 1990-3.

14 Schachat AP, Shields JA, Fine SL, Sanborn GE, Weingeist TA, Valenzuela RE, et al. Combined hamartomas of the retina and retinal pigment epithelium. Ophthalmology 1984; 91: 1609-15.

15 Wise GN. Congenital preretinal macular fibrosis. Am 7 Ophthalmol 1975; 79: 363-5.

16 Laatikainen L, Punnonen E. 'Idiopathic' preretinal macular fibrosis in young individuals. Int Ophthalmol 1987; 10: 11-4.

17 Clarkson JG, Green WR, Massof D. A histopathologic review of 168 cases of preretinal membrane. Am $\mathcal{F}$ Ophthalmol 1977; 84: $1-17$.

18 Gloor BP. On the question of the origin of macrophages in the retina and the vitreous following photocoagulation (autoretina and the vitreous following photocoagulation (autoradiographic investigations by means of H-thym

19 Kampik A, Green WR, Michels RG, Nase PK. Ultrastructural features of progressive idiopathic epiretinal membrane removed by vitreous surgery. Am $\mathcal{F}$ Ophthalmol 1980; 90 797-809.

20 Laqua H, Machemer R. Clinical-pathological correlation in massive periretinal proliferation. Am $\mathcal{F}$ Ophthalmol $1975 ; 80$. 913-29.

21 Laqua H. Pigmented macular pucker. Am f Ophthalmol 1978; 86: $56-8$.

22 Stallard HB. A case of intra-ocular neuroma (Von Recklinghausen's disease) of the left optic nerve head. Br 7 Ophthalmol 1938; 22: 11-8.

23 Goldsmith J. Neurofibromatosis associated with tumors of the optic papilla. Arch Ophthalmol 1949; 41: 718-29.

24 Saran N, Winter FC. Bilateral gliomas of the optic discs associated with neurofibromatosis. Am $\mathcal{F}$ Ophthalmol 1967; 64: 89-94. 